\title{
Professional and conscience-based refusals: The case of the psychiatrist's harmful prescription
}

\author{
By Morten Magelssen \\ Post-print version of article published in Journal of Medical Ethics 2017; 43: 841-844.
}

\begin{abstract}
By way of a case story, two common presuppositions in the academic debate on conscientious objection in healthcare are challenged. Firstly, the debate typically presupposes a sharp division between conscience-based refusals based on personal core moral beliefs and refusals based on professional (e.g., medical) reasons. Only the former might involve the moral gravity to warrant accommodation. The case story challenges this division, and it is argued that just as much might sometimes be at stake morally in refusals based on professional reasons. The objector's moral integrity might be equally threatened in objections based on professional reasons as in objections based on personal beliefs. Secondly, the literature on conscientious objection typically presupposes that conflicts of conscience pertain to wellcircumscribed and typical situations which can be identified as controversial without attention to individualizing features of the concrete situation. However, the case shows that conflicts of conscience can sometimes be more particular, born from concrete features of the actual situation, and difficult if not impossible to predict before they arise. Guidelines should be updated to address such "situation-based" conscientious refusals explicitly.
\end{abstract}

\section{Introduction}

When ought we to tolerate health professionals' conscientious refusals to provide services? The normative literature on conscientious objection in healthcare typically makes two key assumptions that might not be warranted. Firstly, the debate typically presupposes a sharp 
division between conscience-based refusals and refusals based on professional (e.g., medical) reasons. Only the former might involve the moral gravity to warrant accommodation.

Secondly, it is typically presupposed that conflicts of conscience involve the infringement of moral or religious norms that can be formulated generally, and thus that the conflict can be foreseen. By way of a case story, this article challenges both presuppositions. Firstly, it is argued that refusals based on professional reasons might sometimes carry the same moral gravity as the more classical refusals based on personal moral or religious beliefs. Secondly, it is shown that there are conflicts of conscience that cannot necessarily be foreseen at the stage where the professional chooses a specialization or accepts a particular job ("situation-based" conflicts of conscience).

Arguably, by making the two assumptions the academic debate on conscientious objection has obscured two important subsets of conflicts of conscience in healthcare: those in which refusals are based on professional reasons, and those which are situation-based and not based on general moral rules. Perhaps such conflicts of conscience are more prevalent - and more important - than has been recognized. Although not a main focus of the article, it is also argued that professional guideline documents on conscientious objection should be updated to encompass these categories of conflicts of conscience. In closing, some reflections on the case story are offered.

\section{The case of the psychiatrist's harmful prescription}

An experienced psychiatrist working in a multidisciplinary team providing long-term followup of patients with chronic psychosis took a part-time position at a small, general psychiatric outpatient clinic in a small Norwegian town. Amongst other tasks the new job entailed providing opioid replacement therapy (ORT) for a handful of patients. ORT involves the prescription of opioids such as methadone or buprenorphine to replace illegal opioids such as 
heroin. ORT has been controversial, and throughout his career the psychiatrist had been critical of prescription of any drugs that could lead to addiction. However, he had never been required to participate in ORT before and accepted his new role in providing the prescriptions.

One day a patient under the care of the psychosis team told the psychiatrist of having received buprenorphine from a named person - and reported the experience with the drug as positive. Opioid abuse, however, is typically severely detrimental for patients suffering from chronic psychosis. The drug seller turned out to have been one of the psychiatrist's new ORT patients; a few days later this latter patient turned up at the psychiatrist's office expecting the regular buprenorphine prescription.

The psychiatrist complied, but the experience was a turning point for him. ORT programs carry a risk of prescribed opioids entering the illegal market. For the psychiatrist, however, this problem which was well known to him had here gone from theoretical risk to a practical reality where he himself was involved. The realization that drugs provided by him to one patient were likely to end up severely damaging another patient under his care set off an emotional reaction which he later described as "a sickening feeling, an inner turmoil," and "a terrible feeling of guilt and complicity". Feeling powerless to prevent the patient from reselling the drugs, he decided he could not continue providing such harmful prescriptions.

For the psychiatrist, the situation had turned into a conflict of conscience. He asked the head of the clinic to be released from responsibility for the ORT patients and requested that the dilemmas experienced be discussed among the colleagues. The head of the clinic requested a clinical ethics committee (CEC) consult on the specific issue of conscientious refusal in this case. The CEC discussed this issue without further involvement of the stakeholders, concluding with the advice that the department ought to accommodate the psychiatrist's request if possible even though there is no juridical provision for conscientious 
objection in cases such as these. The psychiatrist consulted the Norwegian Medical Association (NMA) about opportunities for conscientious objection. The NMA's written response was that, compared to more classical conscientious objection situations, the psychiatrist's objections "are of a more medical and societal kind, and most likely do not satisfy the demand of serious reasons of conviction". Therefore, according to the NMA, professional ethics guidelines could not justify conscientious objection in this case.

The psychiatrist was the only doctor at the outpatient clinic; therefore, there was no colleague to whom the ORT tasks could be transferred. The closest alternative clinic was located an hour's bus travel away. Due to this and in light of the NMA's verdict the psychiatrist very reluctantly decided to continue prescribing ORT medication; when his shortterm contract ended some months later he did not opt to extend it.

\section{Professional versus conscience-based refusals}

According to Mark R. Wicclair's definition, health professionals

engage in acts of conscientious objection when they: (1) refuse to provide legal and professionally accepted goods or services that fall within the scope of their professional competence, and (2) justify their refusal by claiming that it is an act of conscience or is conscience-based. ${ }^{1, p .1 .}$

For a refusal to be what Wicclair calls conscience-based it must involve a core moral belief. ${ }^{1}$ Similarly, Robert F. Card's view requires that conscientious objection, in order to merit toleration, "be grounded in a core genuinely held moral belief". 2 Supporters of conscience rights in healthcare often point to the importance of the health professional's moral integrity as the fundamental justification for tolerating conscientious refusals: if you make a healthcare professional act against their conscience, this violates their 
moral integrity. Therefore, conscientious refusals should be accommodated if certain further criteria are fulfilled. ${ }^{1,3-5}$

However, when health professionals disagree about professional (e.g., medical) practices the contesting views are not necessarily core moral beliefs that are deeply held in the sense of being central to the professional's moral identity. Wicclair therefore distinguishes refusals based on professional or clinical norms on the one hand, from refusals based on personal ethical or religious belief (i.e., conscience) on the other. ${ }^{1}$ When one is forced to act against professional/clinical norms one might experience moral distress, the phenomenon that one is unable to do what one perceives as correct due to institutional constraints. Moral distress involves unpleasant psychological and emotional experiences. However, for conscience-based refusals, lack of toleration and forced compliance can result in "an act of self-betrayal" that can be "devastating and unbearable" and is likely to involve experiences of "guilt, remorse, loss of self-respect, and/or shame". 1, p. 8, ${ }^{11}$ Wicclair thus distinguishes sharply between health professionals' conscience-based and professional refusals to provide services. The differences between conscience-based and professional refusals are summarized in Table 1.

Table 1. Characteristic features of conscience-based and professional refusals according to Wicclair $^{1}$

\begin{tabular}{|l|l|l|}
\hline Feature & Conscience-based refusals & Professional refusals \\
\hline Basis & $\begin{array}{l}\text { Personal ethical or religious } \\
\text { beliefs }\end{array}$ & Professional norms and \\
standards \\
\hline beliefs & $\begin{array}{l}\text { Core moral beliefs, } \\
\text { fundamental and integral to } \\
\text { person's moral identity }\end{array}$ & Do not form part of person's \\
\hline
\end{tabular}




\begin{tabular}{|l|l|l|}
\hline Experienced & Act of self-betrayal & Act that is \\
significance of acting & & morally/professionally \\
against moral beliefs & inappropriate \\
\hline Potential emotional & Guilt, remorse, loss of self- & Moral distress \\
repercussions & respect, shame & \\
\hline
\end{tabular}

The psychiatrist's story, however, challenges this clean-cut distinction. Apparently, his moral conflict was rooted not primarily in any personal ethical beliefs, but in professional judgement and norms. The psychiatrist's realization that his participation in ORT was damaging other patients under his care can be thought to have actualized important professional norms; in particular, the duty not to do harm, and the special duty towards weak or underprivileged patients (here, patients suffering from chronic psychosis; these patients might display reduced reasoning skills and willpower and therefore require extra attention and protection from healthcare professionals). On my interpretation, the harmful prescription practice did not challenge core "personal" moral norms, but took on a strong moral gravity due to the severe negative consequences for the patients potentially harmed thereby. The psychiatrist's "terrible feelings of guilt and complicity" testify to the experienced moral seriousness of the courses of action he was led to take. In terms of the human goods at stake the moral conflict is very serious: In the psychiatrist's estimation, the psychosis patient's budding drug abuse was likely to be extremely harmful, thwarting progress and threatening serious deterioration and perhaps addiction.

The case illustrates that a violation of professional norms can be experienced as so morally serious that it induces strong feelings of guilt and a strong wish to refrain from providing the service; the same phenomena that Wicclair claims are characteristic of classic 
conscientious objection on grounds of "personal" moral beliefs. Apparently, moral integrity can come under equal threat in both kinds of conflicts of conscience.

In one sense this should be unsurprising. Medicine is a moral activity where important human goods are often at stake ${ }^{6}$ professional/medical judgements will often have a moral component. ${ }^{7}$ Conceivably, for the dedicated professional, professional values and norms might become integrated into their moral identity, taking on a "personal" character and significance. ${ }^{8}$ Christopher Cowley points out that some refusals can be grounded in the professional's conception of the nature of their vocation or calling. ${ }^{9}$

Because of the literature's emphasis on "personal” beliefs, perhaps the moral importance of some dilemmas involving professional norms have not been fully recognized. One example of conscientious objection based in professional norms is when surgeons refuse to perform complex and risky operations on patients who refuse blood transfusions; for the surgeon, the increased risk of intra- or postoperative death, avoidable with transfusions, can be perceived as morally unacceptable. Another example described is when nurses object to participation in invasive procedures where pain relief is inadequate. ${ }^{10}$

A note on terminology: Wicclair reserves the term "conscience" for moral conflicts where personal core beliefs are at stake. However, in a wider sense, "conscience" may refer to the faculty of judging the moral character of acts. In this sense, the view that a certain action is morally prohibited because violating professional norms is also a judgement of conscience, even though not involving personal core beliefs. In the present section I have used Wicclair's terms, but in the remainder of the paper I take "conflicts of conscience" and "conscientious objection" to be umbrella terms encompassing moral conflicts and refusals based on either personal core beliefs or professional judgements.

\section{Situation-based versus principle-based conflicts of conscience}


In guidelines and in the normative literature on conscientious objection in healthcare, a prevalent implicit assumption is that the conflict of conscience pertains to a wellcircumscribed and typical situation which can be identified as controversial without attention to individualizing features of the concrete situation. Such conflicts of conscience are "principle-based", in that they involve general moral principles, such as the moral prohibition on killing. However, the present case shows that conflicts of conscience can sometimes be more particular, born from concrete features of the actual situation, and difficult if not impossible to predict before they arise. In a recent paper, Steven W. Smith discusses such cases, pointing out that "doctors might object to particular instances which are not necessarily covered by (predictable) generalisable rules". ${ }^{11}$ I suggest that such conflicts of conscience be termed "situation-based", as opposed to the more commonly acknowledged principle-based conflicts.

For the clinician, day-to-day work in clinical practice will range from mundane tasks to complex, morally laden and highly important decision-making and interventions. Variation may be endless and situations which can amount to conflicts of conscience for the involved parties cannot always be predicted. Indeed, perhaps situation-based conflicts of conscience such as the one illustrated in the case are more common than has been realized. To give three examples: Firstly, a gynaecologist with few qualms about selective fetal reduction may still find a concrete proposal for reduction of a twin pregnancy without any medical justification morally unacceptable. Secondly, as Dominic Wilkinson has discussed, physicians could refuse to take part in treatment (e.g., intensive care) that they in a specific instance deem futile or too costly, ${ }^{12}$ even though they have no objections to such treatment in other situations. Thirdly, a Dutch physician who has performed euthanasia several times might refuse to do so in a concrete situation where mental illness contributes to the totality of symptoms, even though the patients fulfils all the formal criteria for euthanasia. Since substantial human goods 
are at stake, such situations may rise above the level of moral discomfort characteristic for moral distress, and resemble the more classical conflicts of conscience and perhaps give rise to conscientious refusals.

Wicclair and others speak of conflicts of conscience and conscientious refusals as arising from core moral beliefs that tend to be persistent over time. Thus, the practices that the professional will find morally problematic can be precisely delineated and identified ahead of time. However, could it not be the case that the particular situation, with all the individualizing features, in which the practitioner finds themselves here and now, appears morally problematic to the same degree as in a foreseeable conflict of conscience? The psychiatrist held no "core moral belief" that ORT was morally wrong. Yet, much that was of moral importance was at stake, as the act expected of the psychiatrist was, he perceived, likely to harm patients under his care. Whether the act goes against long-standing moral principles in the form of core moral beliefs, or rather is deemed morally prohibited in light of how all the particular features of the situation add up, is arguably of subordinate importance. ${ }^{i}$ What is decisive, on the other hand, is the moral significance - the degree of moral wrongness all things considered - of the act the professional is expected to perform. The threat to moral integrity can be equally severe in situation-based conflicts of conscience as in principle-based conflicts.

\section{Normative consequences}

The argument so far is that the academic debate has mostly focused on conflicts of conscience that involve personal core moral and religious beliefs and that are principle-based and foreseeable, thereby neglecting conflicts of conscience that involve professional norms and that are situation-based and unforeseeable. Furthermore, it has been argued that these two distinctions do not in themselves make a difference to the moral importance of the conflict of 
conscience. Moral integrity may be threatened to an equal degree whether the conflict of conscience is based on personal core moral beliefs or professional norms, whether principlebased or situation-based.

Arguably, therefore, the moral gravity of the conflict of conscience, and not the abovementioned characteristics of the conflict, is the factor that prima facie justifies workplace and societal toleration of conscientious refusals.

If these contentions are right, this indicates that health professionals' moral integrity is insufficiently protected by policies in which toleration of, and procedures for, conscientious objection in specified circumstances (i.e., abortion, assisted dying) are agreed on at the time a healthcare professional is hired. In order to cover unforeseen yet serious situation-based conflicts of conscience professional guidance must be more general.

The UK's General Medical Council (GMC) has issued guidelines pertaining to conscientious objection. ${ }^{13}$ As stated in $\S 8$ of "Personal beliefs and medical practice", as a health professional you "may choose to opt out of providing a particular procedure because of your personal beliefs and values". 13 Among important restrictions on this option are the requirements that conscientious refusals do not lead to (direct or indirect) discrimination or harassment, and that the employer's right to require specified contractual requirements be met. Although the GMC's document ${ }^{13}$ in general is accepting of conscientious refusals, it is clearly written with the paradigm cases of principle-based, foreseeable objections based on personal core beliefs in mind. For instance, advance notification of patients $(\S 10)$ and advance discussion with employers and colleagues $(\S 11)$ is advised; ${ }^{13}$ this would not necessarily be possible in situation-based conflicts, as in the case story. It is implied that objections are based on "personal beliefs" (values, cultural practices; $§ 1, \S 3, \S 8) .{ }^{13}$ Arguably, it is unclear how the GMC's guidance should be applied in cases of situation-based refusals or 
refusals based on professional norms. Guidelines such as the GMC's should be updated to address these two categories explicitly.

This leads to the normative question of whether the psychiatrist's conscientious refusal ought to be tolerated in this case. Elsewhere I have argued that in general, it is morally right to tolerate conscientious refusals when the health professional's moral integrity is truly at stake and accommodation can be achieved in practice without unacceptable burdens for patients, colleagues and employers. ${ }^{3}$ As has been argued, a conscientious refusal arising from a situation-based conflict of conscience based on professional norms has the same prima facie claim to toleration as a refusal arising from a principle-based/foreseeable conflict based on "personal" core beliefs, given that the moral conflict is equally important. The decisive factor is the threat to moral integrity. Much was at stake for the psychiatrist in this case; it is reasonable to characterize his conflict of conscience as a threat to moral integrity. The psychiatrist's refusal therefore has a prima facie claim to accommodation. Pace the Norwegian Medical Association, sufficiently much is at stake morally for the psychiatrist for toleration of his refusal to be justified.

Can his refusal be accommodated? If colleagues were available, the entire follow-up of ORT patients could perhaps be transferred to them without undue burdens. However, the psychiatrist was the only physician at the institution. A monthly two-hour bus travel to the closest institution would burden the ORT patients; whether this burden would be unacceptable is probably a point of contention. One might well conclude that the unavailability of colleagues locally tips the moral balance in the psychiatrist's disfavour: for the sake of the interests of the ORT patients, the psychiatrist's conscientious refusal should then not be tolerated.

A morally important difference between situation-based and principle-based conscientious refusals is that as the former arise in a specific situation, they cannot be 
foreseen and plans for accommodation cannot be made beforehand. Thus, when the need arises it might be less feasible to arrange for the transfer of care to a colleague.

Accommodation of the conscientious refusal without undue burdens to patients might therefore not be possible. In such cases, refusals should not be accommodated.

Arguably, a general legal protection of a right to refuse provision of services in the context of situation-based conflicts of conscience would not be justified. A legal right would give the health professional too much power to override the legitimate interests of the patient and employer. A generally formulated law would not be sufficiently sensitive to these interests. However, as has been argued, toleration of conscientious refusals might very well be morally justified in situation-based conflicts, where moral integrity is indeed at stake for the professional and accommodation is feasible without undue burdens for patients and employers. If possible and if time allows, employers and professionals should seek out solutions that are practicable, taking the local context into consideration.

\section{Concluding reflections on the case}

Returning to the case, how should the clinic have reacted to the conflict? When a clinicalethical conflict arises, the situation should ideally spur a discussion among employees and leaders at the clinic. Pros and cons with present practices should be openly discussed, with a view to addressing problems and improving practices. Perhaps such collective reflection could have led to ideas for changes such as dispensing opioids at the pharmacy in smaller quantities or other forms of tighter control. In its essence, ORT involves a moral compromise; it is surely not unproblematic that we as societies "treat" addiction with opioids, thus instructing physicians to dispense harmful and addictive drugs for what is not merely (or even primarily) a medical but also a social "disease". Practitioners in this field should have access 
to moral deliberation about the practice's inherent dilemmas and the moral conflicts experienced in practice.

It is a task for department leadership to facilitate free and open debate of dilemmas in the intersection between clinical practice, organization and ethics. In a 2010 survey among Norwegian physicians it was found that experiences of moral distress were prevalent and that many considered freedom of expression in hospitals to be limited due to fear of retaliation from the management. ${ }^{14}$ In the case at hand the psychiatrist appeared to have been left to handle his dilemma on his own without the benefit of such open discussions. The CEC could have been a useful venue for such discussion with the health professionals and leaders involved present.

The argument of this paper has been that moral conflicts based on professional norms or that are situation-based instead of principle-based have been overlooked in the debate on conscientious objection. Are such conflicts exceptional, or are they perhaps more prevalent and morally more important than has typically been recognized? If the latter, then this is an additional argument for a climate of openness and tolerance in the clinic. Ideally, in a climate of openness to the discussion of experienced dilemmas, and of tolerance towards differing viewpoints, one is not afraid to allow critical questions, moral conflicts and distress to surface. On the contrary, the cultivation of moral sensitivity is encouraged and recognized as a virtue to be put in the service of patients. Indeed, as openness and tolerance may facilitate improved practices and creative, practically workable solutions to experienced moral dilemmas, such a workplace climate may serve to prevent the development of a need for outright refusals of participation in controversial practices. Sometimes it may also turn out that the experience of having been taken seriously by colleagues and management and having had the occasion to discuss one's moral dilemma reduces the felt necessity to refuse participation in the practice. 


\section{References}

1. Wicclair MR. Conscientious Objection in Health Care. Cambridge: Cambridge University Press, 2011.

2. Card RF. The Inevitability of Assessing Reasons in Debates about Conscientious Objection in Medicine. Cambridge quarterly of healthcare ethics. 2017; 26: 82-96.

3. Magelssen M. When should conscientious objection be accepted? J Med Ethics. 2012; 38: $18-21$.

4. Fovargue S and Neal M. 'In Good Conscience': Conscience-Based Exemptions and Proper Medical Treatment. Med Law Rev. 2015; 23: 221-41.

5. Brock DW. Conscientious refusal by physicians and pharmacists: who is obligated to do what, and why? Theoretical Medicine and Bioethics. 2008; 29: 187-200.

6. Pellegrino ED and Thomasma DC. The virtues in medical practice. Oxford: Oxford University Press, 1993.

7. Wilkinson D. Conscientious Non-objection in Intensive Care. Cambridge quarterly of healthcare ethics. 2017; 26: 132-42.

8. Neal M and Fovargue S. Conscience and Agent-Integrity: A Defence of ConscienceBased Exemptions in the Health Care Context. Med Law Rev. 2016; 24: 544-70.

9. Cowley C. A Defence of Conscientious Objection in Medicine: A Reply to Schuklenk and Savulescu. Bioethics. 2016; 30: 358-64.

10. Ford NJ and Austin W. Conflicts of conscience in the neonatal intensive care unit: Perspectives of Alberta. Nursing Ethics. 2017. Published online 4 Jan 2017.

11. Smith SW. A bridge too far: individualised claims of conscience. Med Law Rev. 2015; 23: $283-302$.

12. Wilkinson D. Rationing conscience. J Med Ethics. 2016. Published online 12 Oct 2016.

13. General Medical Council. Personal beliefs and medical practice. 2013.

14. Førde R and Aasland O. Moral distress and professional freedom of speech among doctors. Tidsskrift for Den norske legeforening. 2013; 133: 1310-4. 


\begin{abstract}
${ }^{\mathrm{i}}$ A situation-based refusal can also be construed as being grounded in moral principles, such as the principle of nonmaleficence. In this sense, a situation-based refusal can also be said to be "principle-based". However, the distinguishing feature of a situation-based refusal is that it is not grounded in the principled opposition to a specific, well-demarcated medical procedure, and thus is not foreseeable.
\end{abstract}

